\title{
LETTER
}

\section{Electrical muscle stimulation for prevention of critical illness polyneuropathy}

\author{
Pablo O Rodriguez ${ }^{* 1,2}$, Mariano Setten ${ }^{1,3}$ and Ricardo Valentini', \\ See related research by Routsi et al., http://ccforum.com/content/14/2/R74
}

We read with interest the study by Routsi and colleagues showing that electrical muscle stimulation (EMS) reduced the frequency of critical illness polyneuropathy in intensive care unit (ICU) patients [1]. The authors stated that an intention-to-treat analysis was used. One hundred and forty patients were randomized to electrical stimulation or to usual care. Measurement of the main outcome could only be performed in cooperating patients surviving after awakening. Thus, 39 patients (57\%) and 44 patients (61\%) who died or who had impaired cognitive state were excluded from analysis in each arm. Data from five out of 29 subjects on the intervention arm were also excluded from the final analysis because of neuromuscular blocker use $(n=3)$ or a lack of electrical stimulation during the ICU stay $(n=2)$. The latter probably induced a selection bias, as subjects receiving neuromuscular blockers have increased risk of critical illness polyneuropathy and patients with this condition have not been excluded from the usual care group [2]. The authors reported other outcomes such as duration of mechanical ventilation or ICU length of stay for patients with strength score evaluation, while analysis in all randomized subjects could have been valuable.

Finally, reported strength scores represented the addition of upper and lower extremities, while stimulation was only applied to the latter. As systemic effects of EMS have not been definitely established in this setting, it would have been interesting to compare the strength of muscles where the intervention was tested.

\section{Authors' response}

Serafim Nanas

We thank Dr Rodriguez and colleagues for their interest in our study [1]. We agree that some selection bias could exist because we excluded patients receiving neuromuscular blocking agents in the EMS group but not in the control group. This was not, however, the case in our study. Among the patients that could be finally evaluated for critical illness polyneuromyopathy $(n=52)$, only one patient - assigned to the control group - received prolonged neuromuscular blockade agents. As this patient was not diagnosed with critical illness polyneuromyopathy (Medical Research Council score 52 ), this case could not affect our results.

Secondly, the duration of mechanical ventilation, the duration of weaning and the ICU length of stay are

\footnotetext{
*Correspondence: prodriguez@cemic.edu.ar
}

'Intensive Care Unit, CEMIC (Centro de Educación Médica e Investigaciones

Clínicas), Av. Las Heras 2900, C1425ASS Buenos Aires, Argentina

Full list of author information is available at the end of the article reported in all patients that were randomized regardless of whether they could be evaluated with the Medical Research Council scale for muscle strength.

Finally, in a previous study by our group [3] we showed that EMS of lower extremities has an acute systemic effect on the microcirculation of critically ill patients. Moreover, the data of our recent study [1] - showing a shorter duration of weaning in patients assigned to the EMS group indicate a long-term systemic effect of EMS. The effect of EMS of lower extremities on the muscle strength of upper extremities is relevant, but this was not the scope of the study. We agree, however, that this is of interest and deserves to be examined in a further study.

\section{Abbreviations}

EMS, electrical muscle stimulation; ICU, intensive care unit.

\section{Author details}

'Intensive Care Unit, CEMIC (Centro de Educación Médica e Investigaciones Clínicas), Av. Las Heras 2900, C1425ASS Buenos Aires, Argentina. ${ }^{2}$ Instituto Universitario CEMIC, Galvan 4102, C1431FWO Buenos Aires, Argentina. ${ }^{3}$ Department of Physiotherapy, CEMIC, Av. Las Heras 2900, C1425ASS Buenos Aires, Argentina. 


\section{Competing interests}

The authors declare they have no competing interests.

Published: 12 July 2010

\section{References}

1. Routsi C, Gerovasili V, Vasileiadis I, Karatzanos E, Pitsolis T, Tripodaki ES, Markaki $\checkmark$, Zervakis D, Nanas S: Electrical muscle stimulation prevents critical illness polyneuromyopathy: a randomized parallel intervention trial. Crit Care 2010, 14:R74

2. Garnacho-Montero J, Madrazo-Osuna J, Garcia-Garmendia JL, Ortiz-Leyba C, Jimenez-Jimenez FJ, Barrero-Almodovar A, Garnacho-Montero MC,
Moyano-Del-Estad MR: Critical illness polyneuropathy: risk factors and clinical consequences. A cohort study in septic patients. Intensive Care Med 2001, 27:1288-1296.

3. Gerovasili V, Tripodaki E, Karatzanos E, Pitsolis T, Markaki V, Zervakis D, Routsi C, Roussos C, Nanas S: Short-term systemic effect of electrical muscle stimulation in critically ill patients. Chest 2009, 136:1249-1256.

doi:10.1186/cc9081

Cite this article as: Rodriguez PO, et al.: Electrical muscle stimulation for prevention of critical illness polyneuropathy. Critical Care 2010, 14:428. 